\title{
Meet the Editor
}

\author{
Interview by Kate Quinlan
}

Heather Bradbury joined the BDJ as Assistant Editor in January 2020. In July 2021, following Jonathan Coe's departure to re-train as an English teacher, Heather was appointed Editor of the BDJ and BDJ Open.

\section{What did you study at university and where?}

I studied English Literature at the University of Warwick.

\section{Did you have ambitions to work in publishing?}

Like a lot of students at school, I wasn't 100\% sure what career path to go down - at one point, I wanted to train to become a pilot! Then, during sixth form, my godfather helped me get a work experience placement at Cambridge University Press in the English Language Teaching department, and I enjoyed it so much, that's when my ambition to pursue a career in publishing began.

\section{Can you outline your career background prior to joining the $B D J$ ?}

My first ever job title was Document Prepper; a six-week summer job essentially prepping medical files to be scanned onto an online database by removing staples and flattening out $\mathrm{x}$-rays etc. Another summer job I had was working as a Customer Service Advisor for my local council, which involved answering calls from parents about their children's school placements. Since graduating from uni in 2017, I have worked full-time at Springer Nature, first as an Editorial Assistant on the Nature Research journals and then as Assistant Editor, and now Editor, for the $B D J$.

\section{How have you found the BDJ Assistant Editor role?}

Very interesting and enjoyable! My favourite thing about the role is how varied it is; some days are spent handling submissions and emailing authors/reviewers, while others are spent copyediting articles and opinion pieces, along with other responsibilities like managing our social media accounts and collecting the necessary legal forms and permissions to publish papers.

\section{Have you learnt a lot about dentistry so far?}

Yes - so much! Before I joined the BDJ, my awareness of dentistry went as far as braces, fillings and biannual trips to the dentist. Now, I find myself reading and editing articles about endodontics, oropharyngeal cancer and molar-incisor hypomineralisation, and actually being able to understand the terminology and place the topic in its wider context. Another thing I hadn't appreciated before was how much oral health is linked to our overall health and wellbeing, and the crucial role GDPs play in spotting oral symptoms which may indicate wider health issues, like head and neck cancer.

\section{What have you enjoyed as Assistant Editor?}

I've really enjoyed interacting with specialists in the field, from authors and reviewers to editors and guest editors. A lot of my job satisfaction comes from helping people, so I enjoy resolving issues for authors and answering their queries. It's also particularly rewarding overseeing the editorial side of things right from initial submission all the way through to publication, and seeing a paper develop at each of the different stages into a finished, polished article.

\section{Was it difficult to adapt to working from home when the pandemic started?}

A bit... to be honest, I just felt lucky that I was still able to do my job and isolate at home at the same time. Looking back, it was all such a blur. I joined the BDJ team in January 2020 and had two months of settling in, getting to know everyone and being trained on various tasks. I was fortunate enough to have fitted

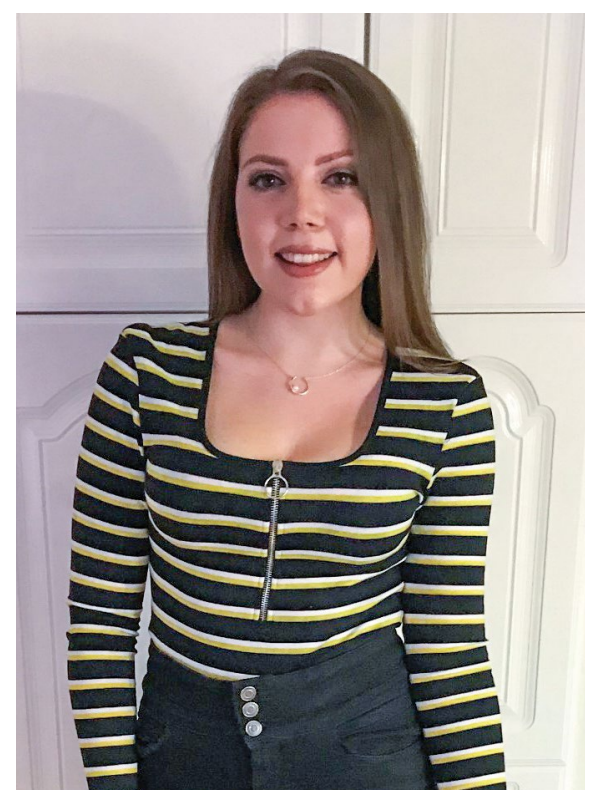

in a holiday to Prague, arriving home on Sunday 8 March, then before I knew it by the following Wednesday, COVID-19 had been declared a pandemic and I was working from home! I still recall our team thinking this would be a temporary precaution, maybe a few weeks or so - almost 18 months later and this has become our new normal!

\section{Are you looking forward to returning to the office?}

Although I have appreciated the extra time working from home has afforded me in terms of not having to commute in and out of London every day, I do miss seeing and socialising with my colleagues as well as other staff in the office. The fact that I get on so well with my team, despite the fact I've spent more time working with them virtually as opposed to in person, just goes to show how welcoming they have all been and is a testament to the strength of our team morale. I'm very much looking forward to seeing them in person again soon, and believe that having the flexibility to spend some days working in the office and some working from home will be a happy medium.

\section{How do you feel to be taking on the Editor role this summer?}

I feel very privileged to be taking on the role of Editor for the BDJ and BDJ Open. It's an exciting step forward in my career, and I welcome the new challenges and increased responsibility it will bring, particularly in 
4 helping to build each issue, contributing to the content we publish, and signing off each print and online publication. I also look forward to working more closely with guest editors and colleagues at the BDA, and the opportunities this will provide to learn from those around me and enhance my awareness of the needs of our readers and the dental profession.

\section{What elements of the role do you think might be more challenging?}

I think the biggest challenge will be adjusting to the new workload and managing my time even more effectively, as I will have more responsibilities to juggle, meetings to attend and multiple different deadlines to hit. Additionally, I will have more accountability and will need to make certain decisions on things, where previously I would have deferred to someone else, so this is quite a step up to adapt to.

\section{What do you look forward to getting your teeth into (pun intended)?}

I'm really looking forward to interacting more with our editorial boards and reader panel, as well as commissioning pieces for our Research Insights section and reaching out to authors with opportunities to write for us. Once they start taking place again, I'm also very excited to go to the dental conferences that I haven't been able to attend since joining the $B D J$. Finally, I'm looking forward to managing and mentoring our new Assistant Editor. believe I am tactful and conscientious, and also very empathetic and diplomatic, which allows me to make good judgement calls and communicate effectively.

\section{What do you do in your spare time?} I enjoy reading, cooking, watching films and playing netball. During lockdown, I also rediscovered some of my old hobbies,

\section{'I feel very privileged to be taking on the role of Editor for the BDJ and BDJ Open. I'm also very excited to go to the dental conferences that I haven't been able to attend...'}

\section{What personal qualities do you have that make you a great editor? \\ Having good time management, a keen eye for detail and a positive attitude. I'm also super organised to the point where I have a spreadsheet for tracking pretty much everything - our previous Editor, Jonathan, used to laugh at this as well as my copious note-taking during training sessions! I}

like playing the piano. Now that restrictions are lifted, I've been making the most of going out for meals and cocktails again with friends and family, and hope to do so with my colleagues again soon.

The BDJ team would like to wish outgoing Editor Jonathan Coe every success in his future career as an English teacher.

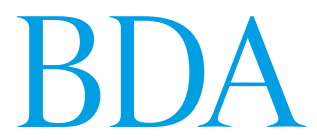

British Dental Association

\section{Members are at the heart of everything we do} Associateships and
employment law

Employment relations

Compliance

Pensions
The business

of dentistry

CPD

Indemnity

\section{Everything you need, in one place.}

Join today

bda.org/membership 